\title{
O CARNAVAL EM PONTA GROSSA E A CO- BERTURA JORNALÍSTICA DO CULTURA PLURAL: OS DESAFIOS DO JORNALISMO CULTURAL NOS CAMPOS GERAIS
}

IVAN BOMFIM UNIVERSIDADE ESTADUAL DE PONTA GROSSA PONTA GROSSA, PARANÁ, BRASIL IVANBP17@GMAIL.COM

KARINA JANZ WOITOWICZ UNIVERSIDADE ESTADUAL DE PONTA GROSSA PONTA GROSSA, PARANÁ, BRASIL KARINAJW@GMAIL.COM

JOÃO GUILHERME CASTRO UNIVERSIDADE ESTADUAL DE PONTA GROSSA PONTA GROSSA, PARANÁ, BRASIL JGCASTRO.JOR@GMAIL.COM

MILLENA VILLANUEVA UNIVERSIDADE ESTADUAL DE PONTA GROSSA PONTA GROSSA, PARANÁ, BRASIL MILLENAVILLANUEVA@HOTMAIL.COM 


\section{O CARNAVAL EM PONTA GROSSA E A COBERTURA JORNALÍSTICA DO CULTURA PLURAL: ASPECTOS DO JORNALISMO CULTURAL NOS CAMPOS GERAIS DO PARANÁ}

Resumo: Este trabalho tem como objetivo apresentar o processo de cobertura jornalística do Carnaval de Ponta Grossa (PR) no ano de 2019 pelos estudantes do curso de Jornalismo da Universidade Estadual de Ponta Grossa participantes do projeto de extensão Cultura Plural. O projeto surgiu em 2011 e desde então realiza coberturas diárias da cena cultural de Ponta Grossa. Em 2019 foi produzida uma cobertura especial do Carnaval da região dos Campos Gerais, compreendendo as cidades de Ponta Grossa e Tibagi (PR). Os resultados aqui apresentados mostram como os estudantes puderam aplicar na prática extensionista novos formatos de cobertura utilizando redes sociais e demais formatos de produção jornalística.

Palavras Chave: Jornalismo Cultural; Carnaval; Extensão Universitária; Cultura.

\section{EL CARNAVAL EN PONTA GROSSA Y LA COBERTURA PERIODÍSTICA DEL CULTURA PLURAL: LOS ASPECTOS DEL PERIODISMO CULTU-} RAL EN LOS CAMPOS GERAIS DE PARANÁ

Resumen: Este trabajo tiene como objetivo presentar el proceso de cobertura periodística del Carnaval de Ponta Grossa (PR) en el año 2019 por parte de los estudiantes del curso de Periodismo de la Universidad Estatal de Ponta Grossa participantes del proyecto de extensión Cultura Plural. El proyecto surgió en 2011 y desde entonces realiza coberturas diarias de la escena cultural de Ponta Grossa. En 2019 se llevó a cabo una cobertura especial del Carnaval de la región de los Campos Gerais, comprendendo las ciudades de Ponta Grossa y Tibagi (PR). Los resultados aquí presentados muestran cómo los estudiantes pudieron aplicar en la práctica extensionista nuevos formatos de cobertura utilizando redes sociales y demás formatos de producción periodística.

Palabras Clave: Periodismo Cultural; Carnaval; Extensión Universitária; Cultura.

THE CARNIVAL IN PONTA GROSSA AND THE JOURNALISTIC COVERAGE OF CULTURA PLURAL: THE ASPECTS OF CULTURAL JOURNALISM IN CAMPOS GERAIS OF PARANÁ

Abstract: This paper aims to present the journalistic coverage process of the Carnival of Ponta Grossa (PR) in the year 2019 by the students of Journalism Curse at Ponta Grossa State University participants in the Cultura Plural extension project. The project started in 2011 and since then realizes 
daily coverage of the cultural scene of Ponta Grossa. In 2019 a special coverage of the Carnival of the Campos Gerais region was produced comprising the cities of Ponta Grossa and Tibagi (PR). The results presented show how the students were able to apply new coverage formats using social media and other forms of journalistic production.

Key-word: Cultural Journalism; Carnival; University Extension Program; Culture.

\section{INTRODUÇÃO}

No presente artigo, trazemos algumas das temáticas, processos e dinâmicas relativas à prática jornalística por parte dos integrantes do projeto de extensão Cultura Plural, realizado no Departamento de Jornalismo da Universidade Estadual de Ponta Grossa (UEPG). Neste sentido, enfocamos a cobertura realizada acerca do carnaval nos Campos Gerais, região paranaense na qual está localizada a cidade de Ponta Grossa. A própria dúvida acerca da existência de festejos momescos na localidade foi um dos elementos de motivação para o planejamento do trabalho dos graduandos, a partir do qual buscamos trazer elementos sociohistóricos para a compreensão dos eventos. Debatemos os elementos motivadores, como a importância de entender festividades da cultura popular, em específico o carnaval em uma região que, aparentemente, não possui essa tradição. Ao mesmo tempo, a possibilidade de atuar em atividade da profissão pelos alunos, com material gravado e transmissões ao vivo, determinou grande interesse do grupo.

O trabalho se configura, portanto, como um relato de experiência fundamentado na atividade extensionista, que utiliza elementos da base de dados do projeto na web (site e mídias sociais) para analisar uma cobertura jornalística de caráter experimental. Em termos metodológicos, são expostas as dinâmicas de trabalho, os indicadores de produção e os aspectos singulares do tratamento jornalístico de uma temática da cultura popular. Desta forma, intencionamos aliar teoria e prática do jornalismo cultural, com especial atenção aos elementos socioculturais que fundamentam sua especificidade.

\section{O POVO EM FESTA: O CARNAVAL COMO UMA TRADIÇÃO POPULAR}

As festas populares representam a cultura de um povo e estão vinculadas aos processos históricos, políticos e sociais que fazem parte da construção de uma identidade. Por este aspecto, tornam-se pauta pertinente ao Cultura Plural, que ao longo de sua trajetória buscou representar diferentes festejos populares ligados à religiosidade, etnia, gastronomia, entre outros que con- 
figuram a região dos Campos Gerais do Paraná.

De acordo com José Marques de Melo (2002, p. 110), enquanto um fenômeno sociocultural, "a festa permeia toda a sociedade, significando uma trégua no cotidiano rotineiro e na atividade produtiva. Sua natureza é intrinsecamente diversional, comemorativa, pautando-se pela alegria e pela celebração". Este aspecto socializador das tradições populares, marcado pela diversão, é uma característica que identifica o Carnaval como uma festa existente em todo território nacional, que assume diferentes formatos de acordo com o contexto, a estrutura, a representatividade e as marcas culturais de uma determinada cidade ou região. Devido aos aspectos singulares, à diversidade das celebrações existentes em todo país e à complexidade das práticas comunicacionais presentes no interior das comemorações, as festas populares se revelaram um importante objeto para os estudos de comunicação e cultura, em especial a partir da perspectiva teórica da folkcomunicação (BELTRÃO, 2004; MELO, 2008).

Em sua abordagem sobre as festas populares, José Marques de Melo (2002, p. 115) identifica diferentes fluxos de comunicação (interpessoais e massivos), que convergem em um processo de múltiplas relações, atribuindo sentido e representatividade para as manifestações culturais. Para o autor,

\begin{abstract}
A gênese da festa localiza-se no imaginário coletivo, sendo resgatada periodicamente através de fluxos de comunicação interpessoal (parentesco, vizinhança, trabalho) que desencadeiam iniciativas de celebração por parte das instituições sociais (escola, igreja, partido, empresa, governo), cuja intermediação comunicativa suscita o interesse dos veículos de difusão coletiva, que a elas se associam, desencadeando fluxos de comunicação massiva, responsáveis pela mobilização dos indivíduos para participar desses atos comemorativos. (MELO, 2002, p. 115)
\end{abstract}

Trigueiro (2007, p. 107) aponta que as festas populares "são acontecimentos identificadores dos fatos locais, são celebrações simbólicas das diversas relações sociais vivenciadas por uma comunidade nos territórios sagrados e profanos". Elas podem ser classificadas de diversas formas, em razão do perfil da celebração, do caráter comercial e dos atores e instituições responsáveis pela sua organização, variando entre celebrações institucionalizadas e espontâneas. No caso do Carnaval, entende-se que, ao mesmo tempo em que se trata de uma festa que mantém fortes vínculos 
com um tipo de tradição popular, principalmente pela trajetória do samba, estilo musical marcado por relações de classe e raça, é inegável que também passa a incorporar a lógica midiática em sua organização e divulgação, deslocando-se de uma cena marginal para os principais veículos de mídia de alcance nacional.

Destarte, falar sobre esta manifestação implica reconhecer importantes variações no modo de festejar, que se desloca dos grandes fenômenos (folk)midiáticos presentes, por exemplo, nos desfiles das escolas de samba em cidades como Rio de Janeiro e São Paulo, com forte apelo turístico e investimentos, ao carnaval de rua com a força dos blocos e trios elétricos no Nordeste do país e, ainda, ao cenário de cidades do interior que realizam o carnaval sem qualquer tipo de apoio institucional por parte do Estado ou de empresas, apenas para manter a tradição da festa. Este é o caso do Carnaval de Ponta Grossa, festa popular realizada desde o início do século XX no interior do Paraná, que tem representado a sobrevivência de uma tradição espontânea, que envolve escolas de samba e, mais recentemente, blocos carnavalescos, em torno de uma celebração que representa a memória e a identidade da cidade.

\subsection{Carnaval em Ponta Grossa'}

No início do século XX é possível perceber a existência do carnaval de rua no município ponta-grossense. Nessa época, de acordo com Juliana Gelbcke, em entrevista ao documentário Um novo Carnaval (CASTRO, VILLANUEVA, 2018), o que existia era o carnaval feito através de blocos a partir de algumas festividades que reuniam os foliões dentro de carros, onde eles lançavam serpentina e confetes nas pessoas. Posteriormente, segundo a historiadora, com a intervenção do Estado na comemoração do carnaval na época de Getúlio Vargas e com o Brasil entrando na Segunda Guerra Mundial, os festejos carnavalescos nas vias da cidade começam a perder força. "Por volta de década de 1940, o carnaval em Ponta Grossa ganha uma nova forma, sendo celebrado dentro dos clubes como o Clube Princesa dos Campos, Clube Verde, Homens do Trabalho, Guarani e o 13 de Maio", observa Gelbcke (CASTRO, VILLANUEVA, 2018). Ele acontece até hoje em algumas

1 As informações sobre o Carnaval em Ponta Grossa estão referenciadas no videodocumentário: "Um novo Carnaval” (CASTRO, VILLANUEVA, 2018). As entrevistas são com os historiadores Fábio Bacila Sahd, Felipe Soares e Juliana Gelbcke. Disponível em: https://youtu.be/FfwJwae2Vqo 
instituições, mas esta forma de celebração também acabou desvanecendo no decorrer dos anos.

A tradição do Carnaval em Ponta Grossa remete também aos operários da ferrovia, que se instalaram no bairro de Olarias e lá fundaram as primeiras escolas de samba. ${ }^{2}$ Atualmente, algumas escolas tradicionais revistem ao tempo e preparam os desfiles na avenida, ao mesmo tempo em que a celebração da festa ocorre nos clubes da cidade e, mais recentemente, nas organizações espontâneas de foliões em blocos nas ruas da cidade.

Hoje em dia, conforme Gelbecke (CASTRO, VILLANUEVA, 2018), uma das principais manifestações carnavalescas da localidade é realizada pelas escolas de samba que ocupam a Avenida Vicente Machado, no centro da cidade, e seguem em direção ao Parque Ambiental, cumprindo um trajeto de pouco mais de um quilômetro de distância. O desfile acontece anualmente, mas é importante ressaltar a dificuldade que as agremiações têm durante os meses pós-festa pela falta de investimento. Em 2019, o carnaval das escolas de samba aconteceu sem nenhum apoio da Prefeitura, com as únicas ações por parte do poder municipal tendo sido a disponibilização de uma caixa de som, um palanque para que os sambas-enredo fossem ouvidos pela avenida inteira e cercas para dividir o público dos participantes do desfile. Mesmo sem apoio institucional, a Liga das Organizações Carnavalescas de Ponta Grossa foi homenageada na Conferência Municipal de Cultura, recebendo o prêmio Roselei do Rocio Manoel de Artes Populares 2019.

Em 2016, iniciou-se um novo ciclo nos festejos de rua feitos por blocos com a primeira edição do Bloco da XV. Um grupo espontâneo e popular que se reunia na Rua XV de Novembro, região central, na terça-feira de carnaval. O movimento teve três edições, na primeira usando a extensão da quadra do Cine-Teatro Ópera, em 2017 aumentando a adesão popular e em 2018 com a rua inteira sendo ocupada por foliões. O bloco encerrou suas atividades em 2018 pelos diversos problemas que ocorreram durante sua terceira edição: falta de controle do público, muitos resquícios de lixo na rua no dia seguinte e casos de assédio, que foram repudiados pelos organizadores.

No mesmo ano, ocorre a primeira edição do Bloco dos Polacos - que, segundo Fábio Bacila Sahd (CASTRO, VILLANUEVA, 2018), surgiu com militantes do PSOL e se tornou um bloco independente. O bloco acontece

2 A Liga das Escolas de Samba reúne as escolas existentes na cidade (tais como Águia de Ouro, Ases da Vila e Globo de Cristal), que se concentram no bairro de Olarias. 
no sábado de carnaval na praça Barão de Guaraúna, também no centro da cidade - conhecida popularmente como a Praça dos Polacos pela existência da igreja Sagrado Coração de Jesus, apelidada de "Igreja dos Polacos" por sua utilização pelos imigrantes poloneses³. Em 2019, há a segunda edição do bloco, que foi sucedido pelo desfile das escolas de samba durante a noite. A motivação para a realização do bloco dos Polacos, na perspectiva de Sahd (CASTRO, VILLANUEVA, 2018), foi "reforçar a agenda do carnaval em Ponta Grossa", celebrando a pluralidade e alegria da cultura brasileira.

A característica jocosa do bloco é destacada por Gelbecke (CASTRO, VILLANUEVA, 2018) ao se referir à apropriação do nome e da identidade eslava na cidade, além do próprio espaço da Praça dos Polacos, onde acontecem os movimentos sociais. Segundo Felipe Soares (CASTRO, VILLANUEVA, 2018),

Historicamente, o ponta-grossense não só gosta do carnaval, de rua ou de salão, como participa do carnaval. As experiências recentes dos blocos de rua na cidade - primeiro com o Bloco da XV, que foi realizado desde 2016 até 2018, e depois com o surgimento do Bloco dos Palacos, em 2018 - mostra a tendência de blocos espontâneos na cidade que não só se refletiu em Ponta Grossa, mas em todo território nacional.

Para Soares (CASTRO, VILLANUEVA, 2018), os blocos, ao realizarem uma apropriação do espaço público, se constituem como movimentos democráticos que representam uma afronta à sociedade conservadora princesiva. Para ele, trata-se de um carnaval de resistência, sem perspectiva econômica.

Pelo viés da folkcomunicação (MELO, 2008), é possível entender que as manifestações da cultura popular aqui relatadas constituem adaptações e recriações das festas carnavalescas, sustentadas em referências do local. Ao valorizar a identidade presente nas tradições da cidade, o Cultura Plural busca se aproximar de um tipo de registro de elementos que, muitas vezes, se situam à margem de uma visão institucionalizada da cultura, legitimada pelas estruturas socioculturais hegemônicas.

3 De acordo com informações da Fundação Municipal de Turismo (http://www.pontagrossa.pr.gov.br/igreja-sagrado-coracao-de-jesus), o templo católico foi erguido em 1928, substituindo construção anterior datada de 1898, em decorrência da necessidade de expansão. Toda a comunicação original no local era realizada na língua polonesa, com exceção das missas, em latim. 


\title{
3 TEORIA E PRÁtICA DO JORNALISMO CULTURAL: A COBERTURA DO CARNAVAL EM PONTA GROSSA
}

A cobertura do Cultura Plural sobre o carnaval de Ponta Grossa implica pensar elementos relacionados ao acompanhamento de eventos no âmbito do jornalismo cultural. Este, de acordo com Faro e Gonçalves (2009, p. 89), trata com uma ampla gama de pautas, mas tendo um denominador comum entre as matérias da editoria, que, ao enfocar um temário de eventos, "oferecem ao leitor, performaticamente, indicações valorativas sobre o conteúdo desses eventos, transitam na esfera do estético-conceitual e/ou do ético-político". Ou seja, há um processo de "leitura" da realidade social, que leva em conta diversos aspectos, tanto manifestos quanto latentes. Neste sentido,

\begin{abstract}
Há, portanto, uma cena cultural construída social-mmente no jornalismo a partir da interveniência de múltiplos fatores - do escrutí-

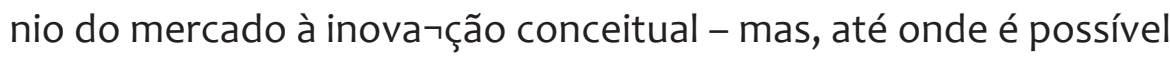
perceber, o elemento preponderante na sua constituição - ainda que não exclusivo - é a ocupação da esfera pública por dois campos sociais que se articulam em função de suas lógicas próprias e dialeticamente interativas (FARO, GONÇALVES, 2009, p. 89).
\end{abstract}

De acordo com Melo (2007), há a conformação de duas dimensões de regularidades no jornalismo cultural. A primeira é a democratização do conhecimento: o noticiário acerca das expressões culturais em todas as suas facetas (festas, celebrações, peças de teatro, programas de televisão, etc) permite que haja acesso a diferentes produções, cada uma referente a processos, lógicas e interesses próprios. Assim, permite-se que diferentes grupos tenham acesso a distintas opções - e, em muitos casos, subvertendo a origem social das manifestações culturais. Um exemplo: por meio da cobertura noticiosa, indivíduos de todos os estratos socioeconômicos que não sabiam da existência da tradição carnavalesca em Ponta Grossa puderam conhecer e participar dos festejos.

A segunda regularidade é o caráter reflexivo. Neste sentido, há uma fundamentação significativa do jornalismo cultural no espectro da análise crítica, o que delineia a possibilidade - e mesmo necessidade - de reflexão acerca do que é noticiado, de decomposição de sentidos e significados, de problematização das dinâmicas apresentadas. O profissional (ou, no caso aqui trabalhado, o profissional em formação) terá um ativo papel de mediação, 
buscando trazer ao público as informações necessárias para a "decodificação" do acontecimento cultural-noticioso. Esta ação passa pela construção de um texto que apresenta, de maneira mais completa possível, o contexto do evento, ao mesmo tempo que, para tanto, a própria emocionalidade pode se constituir um índice de relevância - influenciando na criação de um enquadramento daquela experiência.

De forma geral, a cobertura do carnaval pelo Cultura Plural foi pautada pelas necessidades e possibilidades relacionadas ao universo do jornalismo cultural. Desde o planejamento das pautas, a produção e execução da cobertura, houve a preocupação de apresentar os festejos ao público, trazendo tanto eventos com recorrência anual quanto novas expressões. Neste encadeamento, duas ações se destacam: o processo pedagógico de atuação jornalística dos discentes participantes do projeto extensionista; o conhecimento e a reflexão sobre tradições da região ponta-grossense que foram sendo invisibilizadas ao longo das décadas. Para melhor compreensão dessas dinâmicas, torna-se necessário entender a proposta e o funcionamento do projeto de extensão Cultura Plural.

\subsection{Cultura Plural: extensão universitária e jornalismo}

Projeto desenvolvido desde 2011 no âmbito do curso de Jornalismo da UEPG, o Cultura Plural reúne discentes e docentes na produção de uma cobertura ampla dos eventos culturais que acontecem em Ponta Grossa e região dos Campos Gerais, no Paraná. Com publicação regular, o site do projeto traz informações sobre as mais diversas manifestações artístico-culturais, além de conteúdo produzido por colaboradores. ${ }^{4}$ As temáticas abordadas envolvem shows musicais, apresentações teatrais, exposições artísticas, festas populares, eventos literários, dentre outras.

O projeto extensionista obteve apoio da Fundação Nacional de Artes (Funar-te/Ministério da Cultura) para sua criação e, desde seu projeto original, consi-dera a relevância das ações de grupos e artistas de diversos setores culturais (como artes cênicas, música, patrimônio, religião etc) na região de Ponta Grossa/PR. Desse modo, a equipe do sítio consegue acompanhar ações assim como eventos culturais para serem registrados e difundidos pelas redes soci-ais. Por fim, a equipe também realiza ações de intervenção no espaço público, com a promoção de feiras culturais anuais na 
Semanalmente é realizada uma reunião de pauta, na qual são designados eventos a serem acompanhados pelos graduandos, com supervisão dos professores-coordenadores. A produção noticiosa vai desde a produção de uma agenda semanal à realização de matérias aprofundadas, passando pela publicação de ensaios fotográficos e conteúdos audiovisuais.

Como projeto de extensão universitária no campo do jornalismo, o Cultura Plural busca efetivar a constituição de um saber praxiológico pela aproximação dos discentes à realidade social por meio do conhecimento acadêmico. O Cultura Plural, em sua natureza extensionista, é articulado às lógicas de ensino e pesquisa, intencionando constituir possibilidades de aproximação entre universidade e sociedade por meio da prática jornalística que enfoca o universo cultural - e, desta forma, impactar nas maneiras pelas quais os habitantes dos Campos Gerais possam ver a si mesmos em suas manifestações, tradições e identidades a partir da mídia. O jornalismo, em seu papel de criar narrativas acerca da realidade a partir do interesse público, é uma instância que articula conhecimento, ética e estética. Ao voltar-se à cobertura noticiosa das manifestações carnavalescas, os jornalistas em formação que integram o projeto realizam um processo de aprendizado erigido no encontro entre teoria e prática, cuja baliza está justamente na importância de trazer à esfera pública processos socioculturais e elementos simbólicos que, a depender das mídias comerciais, pouca ou nenhuma atenção teriam. Ademais, os graduandos atuam de maneira a fortalecer o papel cidadão tanto da universidade quanto do universo midiático e, neste encadeamento, compreendem a complexidade e valor social da atividade jornalística.

\subsection{Primeiros movimentos}

Após o período de férias do fim de ano, a retomada do projeto de extensão Cultura Plural no início de 2019 acontece em fevereiro, logo na segunda semana do ano letivo da UEPG. Os alunos participantes passaram pelas salas de aula para convidar os novos estudantes do curso para ingressarem no projeto e também os antigos estudantes a colaborarem numa produção de cobertura especial: o carnaval 2019. Na tarde do dia 26, foram reunidos novos integrantes e também alguns ex-participantes do projeto para definir a cobertura especial. Esta surgiu como uma ideia de pauta nas últimas reuni- 
ões semanais de 2018, quando eram discutidas estratégias para atração de novos integrantes para a ação extensionista. Com a cobertura previamente pautada pela agenda de eventos do período carnavalesco, conseguiu-se garantir acompanhamento para três dias consecutivos: sexta-feira (01 de março), sábado (02 de março) e domingo (03 de março). A cobertura foi publicada no site do projeto (www.culturaplural.sites.uepg.br) e também focada nas redes sociais, em especial o Instagram e o Twitter.

É preciso dizer que foi dada importância significativa à produção e distribuição de conteúdo via redes sociais. A irrupção da chamada Web 2.0 ou Web Social (PRIMO, 2007), cuja base está nos processos de interação e sociabilidade, acabou por ter grande impacto na produção, circulação e consumo jornalístico. As coberturas precisam ser pensadas a partir das lógicas midiáticas contemporâneas, representadas sobremaneira pelas redes sociais, o que implica ter como elementos de importância questões como instantaneidade, interatividade e multimidialidade, tendo o atravessamento decisivo do horizonte da convergência midiática. Assim, ao estabelecer parâmetros de trabalho, a equipe precisa ter em horizonte que o acesso/consumo do material que produzir será feito por meio de distintos dispositivos, o que exige preocupações em relação a elementos técnicos, tecnológicos e conteudísticos.

\subsection{Planejamento}

Na reunião de pauta, foram definidas equipes de reportagem para cada dia do carnaval. Decidiu-se que, quando da presença de novos integrantes do projeto, haveria também a participação de alguns alunos de outras séries do curso para acompanhamento e supervisão das atividades, já que esta seria a primeira experiência jornalística destes estudantes. Depois da distribuição das pautas e definição das equipes, é sempre enviado para os repórteres o planejamento da cobertura semana do projeto. Nesta reunião, são distribuídas outras pautas além do especial do carnaval.

Ainda na fase de planejamento da cobertura, foi criada uma vinheta em vídeo para os Stories do Instagram, anunciando o acompanhamento que seria realizado. Antes também da produção das pautas foram publicados conteúdos de arquivo relacionados ao carnaval. O primeiro foi uma galeria de imagens com o título Outros carnavais ${ }^{5}$, que reuniu fotos das edições 
anteriores das manifestações culturais carnavalescas em Ponta Grossa. O segundo foi a divulgação do videodocumentário Um novo carnaval ${ }^{6}$, produzido para um concurso de videodocumentários. O produto traz um pouco da história do carnaval em Ponta Grossa e também da criação do "Bloco dxs Polacxs" em 2018.

\subsection{Cobertura na prática}

Para o primeiro dia (01 de março, sexta-feira), foram designados quatro repórteres: Ana Istschuk, João Guilherme Castro, Malu Bueno e Millena Villanueva. A cobertura estava agendada pelo evento "Samba do Tranca-Rua", organizado pelo Bloco do Tranca-Rua. O evento foi em estabelecimento privado por conta de entraves nas políticas municipais para a liberação da rua para a realização da comemoração.

Veiculada nas redes sociais, a matéria que foi produzida nesta pauta trouxe o texto e áudio das músicas (imagem 1) e a foto utilizada foi de divulgação. Foram entrevistadas três fontes, sendo: um organizador, um músico e a rainha do samba da cidade. A matéria teve a contribuição de todos os repórteres envolvidos, especialmente, Malu Bueno. Estudante do primeiro ano, integrou o projeto na cobertura especial e teve nesta ação sua primeira experiência jornalística. Considerando que as disciplinas de orientação prática ainda não haviam começado naquele momento, o projeto de extensão serviu como um treinamento para as demais coberturas. A produção de entrevistas no primeiro dia pela graduanda ajudou na produção de entrevistas nos demais dias de evento.

https://culturaplural.sites.uepg.br/?p=3367

6 "Documentário conta história do carnaval de rua em PG". Cultura Plural, 01/03/2019. Disponível em: https://culturaplural.sites.uepg.br/?p=3371 
Imagem 01: Captura de Tela do site na matéria produzida no primeiro dia da cobertura especial do carnaval 2019

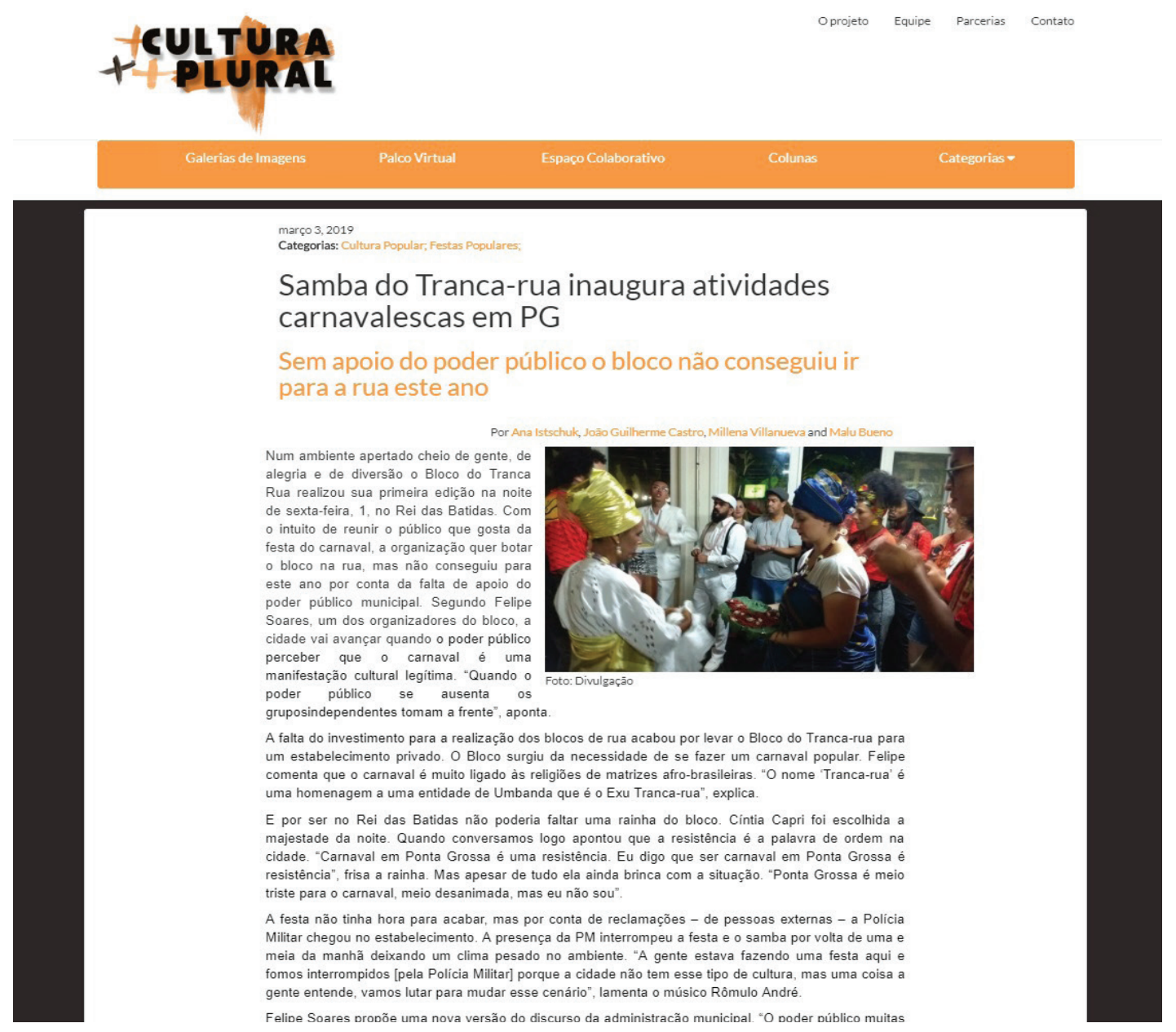

Fonte: https://culturaplural.sites.uepg.br/?p=3386

No segundo dia de acompanhamento (02 de março, sábado), a produção do conteúdo também foi pautada pela agenda de eventos previstos do carnaval de Ponta Grossa. No período da tarde, o evento que motivou a cobertura foi "Bloco dxs Polacxs". Para o trabalho estavam designadas as repórteres Nadine Bianca Sansana e Natália Barbosa. A produção foi uma entrevista com um dos organizadores do bloco. O diálogo foi publicado diretamente no Facebook do Cultura Plural em formato de vídeo (imagem 2). 
Imagem 02: página do Facebook do Cultura Plural com a entrevista do organizador do bloco

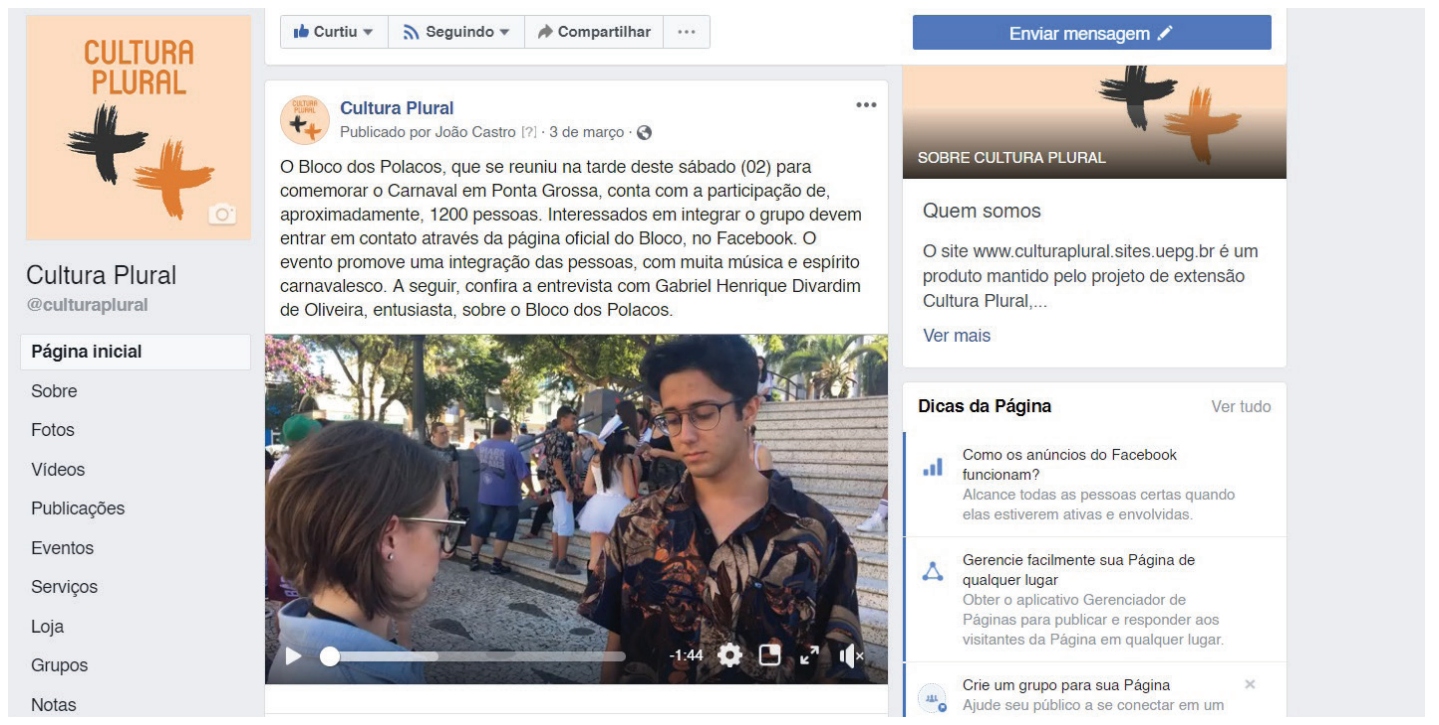

Fonte: Facebook/Cultura Plural

O período da noite de sábado contou com o maior número de repórteres do projeto. Foram oito estudantes diretamente envolvidos em diferentes etapas do processo: Ana Istschuk, João Guilherme Castro, Millena Villanueva, Malu Bueno, Matheus Gastaldon, Solano Ferreira, Rafael Piotto e Yasmin Orlowski. Para esta pauta foram produzidos texto, galeria de fotos, entrevistas e cobertura em tempo real nas redes sociais Instagram e Twitter (imagem 3). Importa notar que, ao mesmo tempo em que é produzido material noticioso sobre os acontecimentos carnavalescos, os integrantes do Cultura Plural questionam a falta de apoio e reconhecimento, por parte do poder público municipal, das manifestações carnavalescas ponta-grossenses. 
Imagem 03: Captura de Tela do site na matéria produzida no segundo dia da cobertura especial do carnaval 2019

\section{tCULTURA
+ PLURAL}

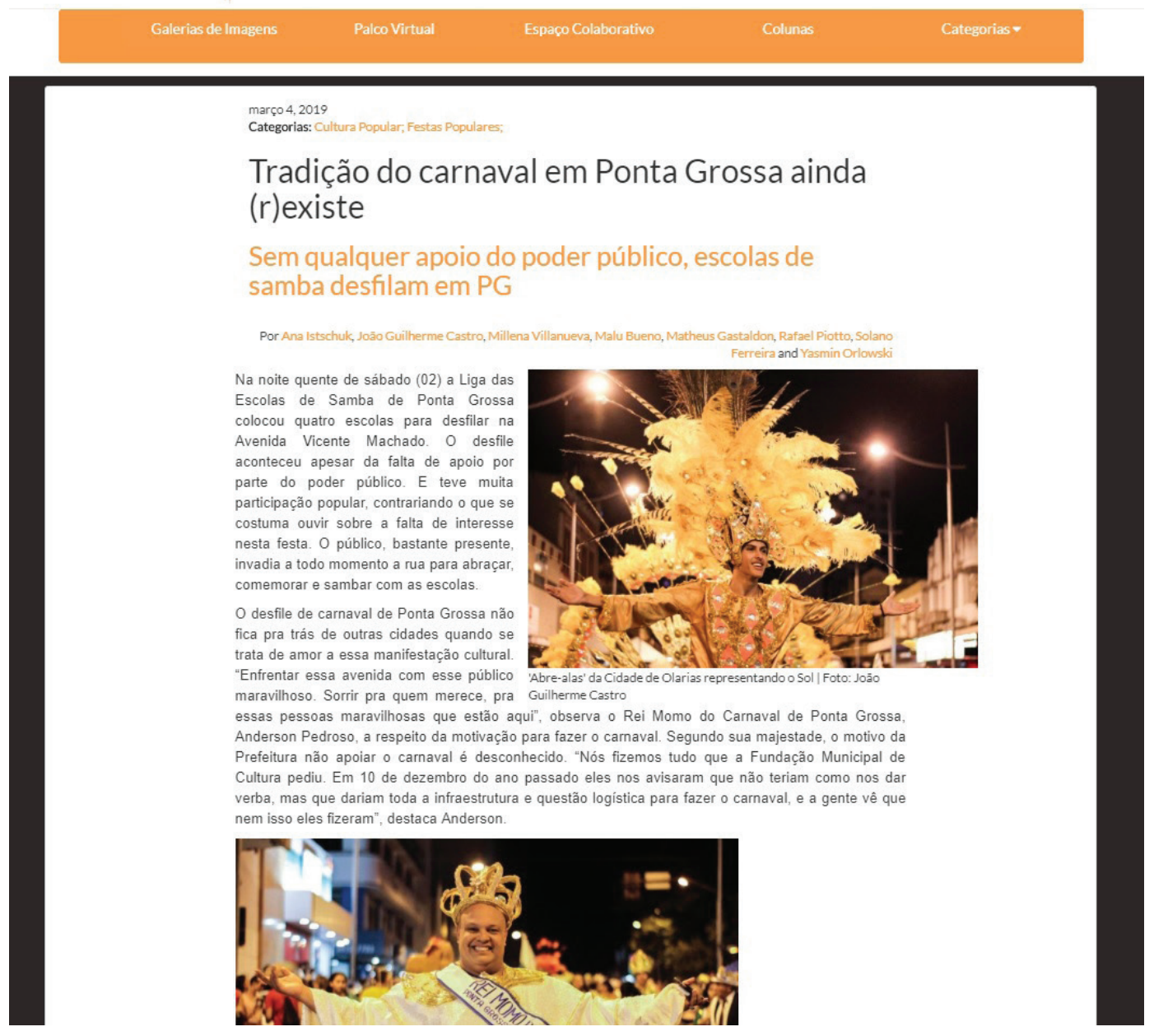

Fonte: https://culturaplural.sites.uepg.br/?p=3389

O ponto forte desta produção foi a atualização constante e contínua dos stories do Instagram, colocando fotos e vídeos das escolas de samba que entravam na avenida para a realização do desfile. Durante esta cobertura nos stories foi realizada uma entrevista ao vivo com o Rei Momo do carnaval ponta-grossense (imagem 4). Para a produção das entrevistas nos stories foi utilizado diretamente o celular e o fone de ouvido conectado como microfone para melhor captura de áudio das fontes. Há também, de maneira clara, a preocupação em utilizar os elementos gráficos que a plataforma permite, como legendas, animações, tags e os chamados emojis, de maneira a efetivar a produção de conteúdo que explore as características particulares da linguagem que é compartilhada pelos usuários do Instagram. 
Ainda nesta cobertura, é interessante destacar o surgimento de um bordão que foi adotado desde então para as produções do site: "Carnaval é Cultura. Se é Cultura, é Plural!”. A frase foi utilizada nos encerramentos das passagens feitas pelos repórteres em vídeo, ao final dos textos e depois, consequentemente, ao final dos textos de outras pautas e aí adaptada à editoria em questão. Por exemplo: “Música é Cultura. Se é Cultura, é Plural!”.

Imagem 04: capturas de tela dos Stories do Instagram da entrevista com o Rei Momo do Carnaval

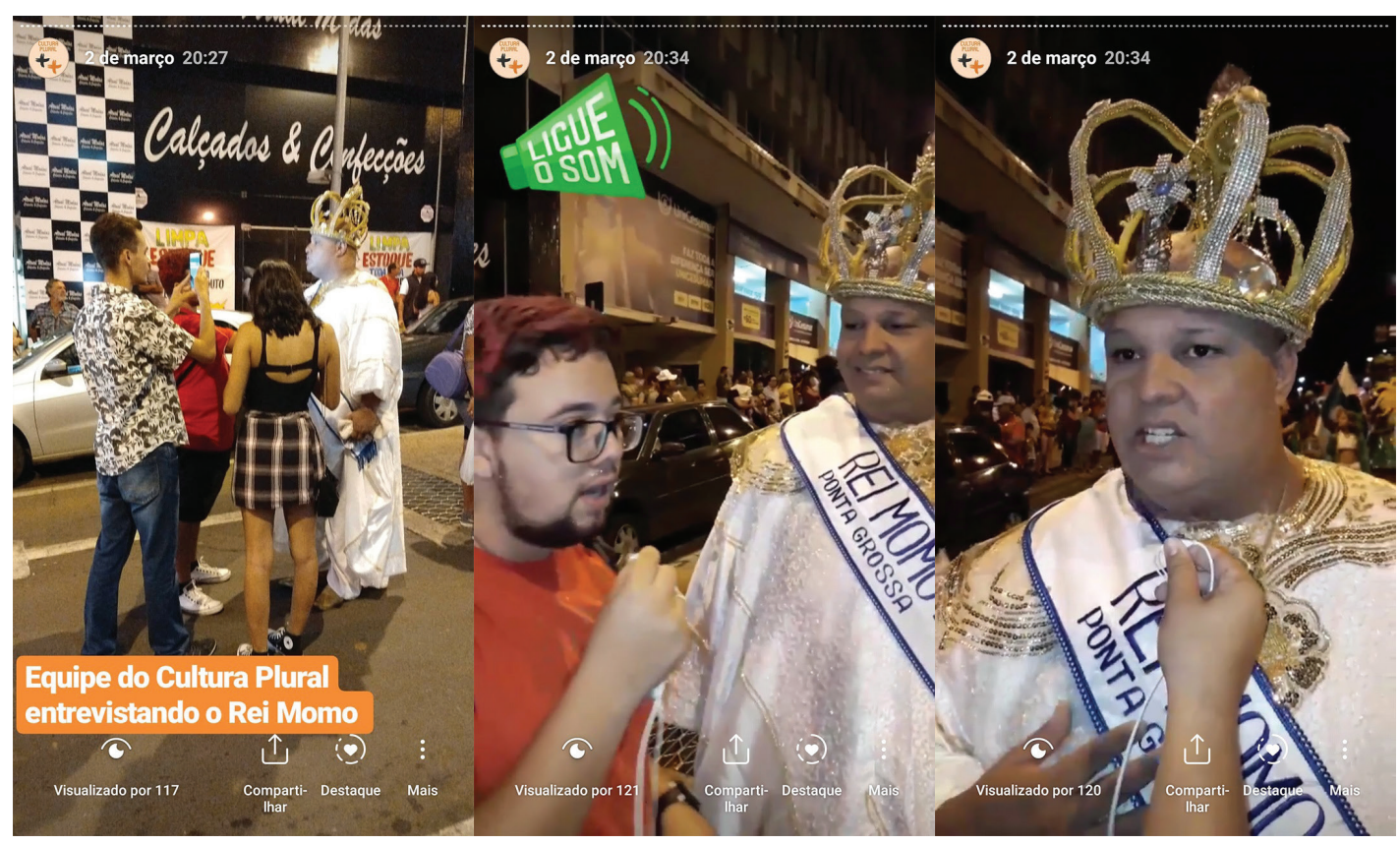

Fonte: Instagram @culturaplural

A finalização da cobertura especial do Carnaval foi na cidade de Tibagi (PR). O município está localizado a aproximadamente 70 quilômetros de Ponta Grossa, maior cidade da região dos Campos Gerais. A equipe do Cultura Plural se deslocou no domingo (03 de março) para acompanhar o desfile do corso na localidade. Participaram deste dia os repórteres Ana Istschuk, Millena Villanueva, Matheus Gastaldon e João Guilherme Castro. A produção neste dia rendeu apenas galeria de fotos (arquivo) e a publicação nas redes sociais Twitter e Instagram. O desfile de Carnaval na cidade não ocorreu como esperado (com escolas de samba e demais características facultadas ao evento carnavalesco), mas sim com grupos de amigos que desfilavam na principal avenida. O evento era conhecido como "desfile do corso".

Foi feita a divulgação da cobertura deste dia também pelo Instagram. Foram anunciadas a ida, a chegada e as produções na cidade. Nos stories 
foram publicadas informações de cada grupo que passava pelo desfile com fotos e vídeos postados na hora. Ao final da parada, os repórteres gravaram passagens em formato TV e também foi realizada uma entrevista ao vivo com divulgação nos stories com o prefeito de Tibagi, Rildo Leonardi, do Movimento Democrático Brasileiro (imagens 5 e 6 ).

Imagem 05: À esquerda, publicação nos stories anunciando a viagem. Ao centro e à direita os repórteres realizando as passagens no modo TV

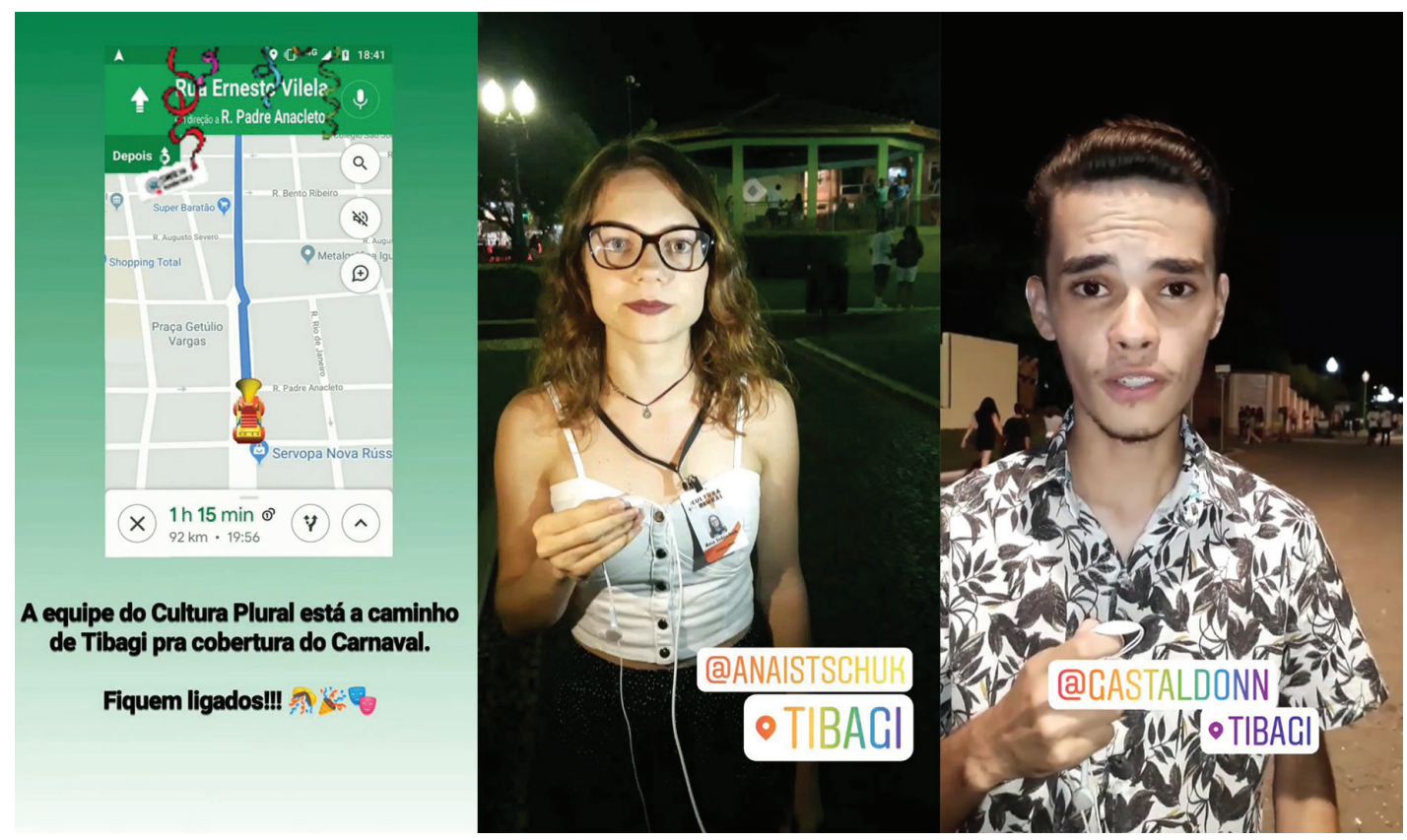

Fonte: Instagram @culturaplural 
Imagem 06: Entrevista com o prefeito de Tibagi, Rildo Leonardi, sobre o carnaval da cidade

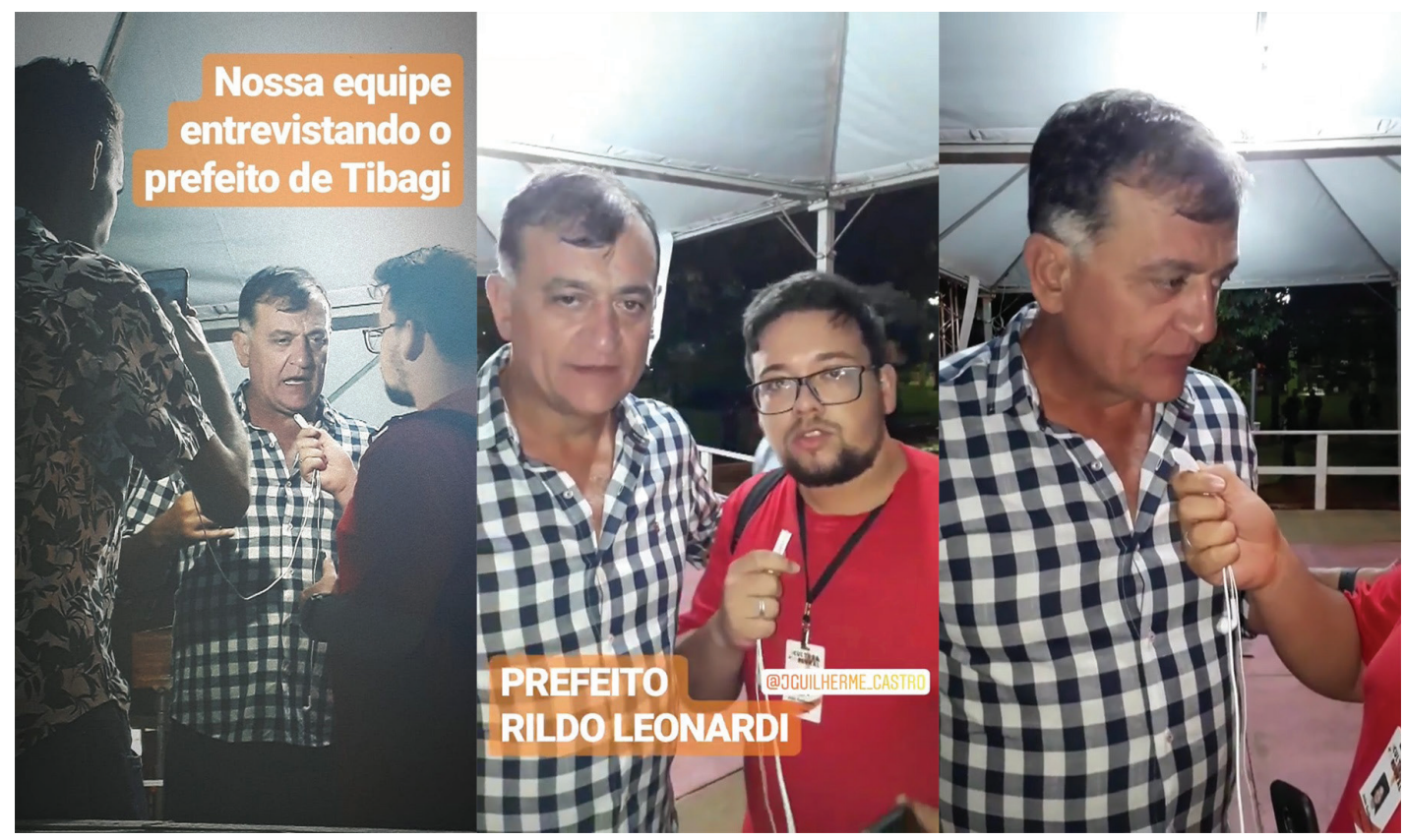

Fonte: Instagram @culturaplural

Após a cobertura, a equipe retornou para Ponta Grossa. Na reunião da semana seguinte do projeto ( 12 de março), foi feita uma avaliação do trabaIho e também uma série de relatos de todos os estudantes envolvidos na atividade, de maneira a ser realizada uma ampla reflexão sobre o processo jornalístico relacionado ao acompanhamento de festas populares - e, especificamente, do carnaval.

\section{CONSIDERAÇÕES FINAIS}

As perspectivas acerca do jornalismo cultural fomentaram o desenvolvimento das pautas e produção da cobertura sobre as festas carnavalescas na região dos Campos Gerais. Trazer à baila um conjunto de celebrações e manifestações em geral midiaticamente invisível, mas social e historicamente relevante, faz com que sejam questionados os processos jornalísticos quando a temática é relacionada a valores que não se apresentam como hegemônicos no espectro da sociedade, por mais importância que possuam. Desde o início, docentes e discentes que compõem o Cultura Plural tiveram como norte a preocupação em dar visibilidade à diversidade constitutiva do carnaval em Ponta Grossa. Neste sentido, o desconhecimento de grande parte da comunidade em relação às tradições e eventos do feriado se mostraram um significativo motivador. De que serve o jornalismo - mesmo quando realiza- 
do de maneira experimental a partir do âmbito universitário - se não dá voz e espaço a diferentes seguimentos sociais? Se não traz a história ou reflete sobre as heranças socioculturais de uma determinada região e sociedade?

Ademais, o alcance da cobertura realizada a partir de dispositivos móveis, com transmissão online para um público virtualmente global, deu a perspectiva de que o Cultura Plural tinha como pauta um evento de grande relevância. Em dimensão macro, uma oportunidade de resgatar e valorizar a história carnavalesca dos Campos Gerais, que dialoga de maneira forte com as camadas populares da cidade. Em um horizonte individual, a experiência com planejamento e execução de trabalho jornalístico ao vivo se mostrou uma forma significativa de aprendizado. É visível, pois, que o horizonte da extensão universitária no jornalismo precisa conjugar o aprendizado técnico-tecnológico aos conhecimentos profundos acerca da realidade social, cultural e histórica, de maneira com que os futuros profissionais possam desempenhar seu ofício com a noção clara da importância do trabalho jornalístico no âmbito geral da sociedade.

Desta maneira, espera-se que, assim como a folia momesca de Ponta Grossa seja resgatada e valorizada, a cobertura por parte dos veículos regionais se torne uma tradição. Causa estranheza, de certa forma, que apenas um veículo jornalístico de caráter universitário se interesse pela produção de matérias e acompanhamento ao vivo de festas que movimentam grande parte dos habitantes dos Campos Gerais, cujo valor histórico e cultural é latente. Não obstante, o trabalho jornalístico ajuda na compreensão das relações sociais em espaços cujos valores e tradições não hegemônicos, por mas que tenham relações profundas com a população, pouco apareçam na esfera midiática local. Entender e narrar a realidade ao seu redor (e que a engendra) é tarefa de enorme importância da instância jornalística. O jornalismo cultural pautado pelo entrelaçamento à comunidade realizado pelo Cultura Plural tem no fortalecimento da identidade local um de seus objetivos e, por que não dizer, sua razão de existir.

\section{REFERÊNCIAS}

BELTRÃO, Luiz. Folkcomunicação: teoria e metodologia. São Bernardo do Campo: Umesp, 2004.

FARO, José; GONÇALVES, Elizabeth. O performativo no jornalismo cultural: uma organização discursiva diferenciada. Revista FAMECOS: Porto Alegre, n. 38, abril de 2009.

LUZ, André; WOITOWICZ, Karina. Jornalismo nas Redes Sociais: Instagram e Facebook 
como Plataformas para Produção de Conteúdo Multimídia pelo Sítio Cultura Plural. Anais do $40^{\circ}$ Congresso Brasileiro de Ciências da Comunicação - Curitiba (PR), 04 a 09/09/2017. MELO, Isabelle. Jornalismo cultural: por uma formação que produza o encontro da clareza do jornalismo com a densidade e a complexidade da cultura. Rumos Jornalismo Cultural, 2007. Disponível em: <http://www.itaucultural.org.br/rumos2007/pdf_jornalismo/Isabelle\%20Anchieta\%20de\%20Melo.pdf>

MELO, José Marques de. As festas populares como processos comunicacionais: roteiro para seu inventário, no Brasil, no limiar do século XXI. Anuário Unesco/Umesp de Comunicação para o Desenvolvimento Regional, n.5. São Paulo: Cátedra Unesco; Universidade Metodista de São Paulo, 2002.

MELO, José Marques de. Mídia e cultura popular: história, taxionomia e metodologia da folkcomunicação. São Paulo: Paulus, 2008.

PRIMO, Alex. Interação mediada por computador: comunicação, cibercultura, cognição. Porto Alegre: Sulina, 2007.

TRIGUEIRO, Osvaldo. Festas populares. In: GADINI, Sérgio Luiz; WOITOWICZ, Karina Janz. Noções básicas de folkcomunicação. Ponta Grossa: Ed. UEPG, 2007.

UM NOVO CARNAVAL. Produção de João Guilherme Castro e Millena Villanueva. Ponta Grossa: Edital 011/2018 do Conselho Municipal de Política Cultura de Ponta Grossa, 2018. (12 min.), son., color. Disponível em: < https://youtu.be/FfwJwae2Vqo>. Acesso em: 07 maio 2019. 


\section{Ivan Bomfim}

Professor do Departamento de Jornalismo e do Mestrado em Jornalismo da da Universidade Estadual de Ponta Grossa (UEPG). Realizou estágios de pós-doutoramento em Ciências da Comunicação na UNISINOS e em Processos Jornalísticos na UEPG. Coordenador do projeto Cultura Plural.

E-mail: ivanbp17@gmail.com

\section{Karina Janz Woitowicz}

Professora do Departamento de Jornalismo e do Mestrado em Jornalismo da Universidade Estadual de Ponta Grossa (UEPG). Realizou estágio pós-doutoral em Comunicação no CIESPAL, Equador. Coordenadora do projeto Cultura Plural. E-mail:karinajw@gmail.com

\section{João Guilherme Castro}

Graduado em Jornalismo pela Universidade Estadual de Ponta Grossa (UEPG), atuou como bolsista do projeto Cultura Plural pela Fundação Araucária/UEPG. Mestrando em Jornalismo na Universidade Estadual de Ponta Grossa.

E-mail: jgcastro.jor@gmail.com

\section{Millena Villanueva}

Estudante de Graduação em Jornalismo na Universidade Estadual de Ponta Grossa (UEPG). Atuou como bolsista do projeto Cultura Plural pela Fundação Araucária/UEPG.

E-mail: millenavillanueva@hotmail.com 